\title{
A REFORMA DO ENSINO MÉDIO E A CONSTRUÇÃO DE NOSSA RESISTÊNCIA EM DEFESA DA EDUCAÇÃO PÚBLICA
}

\author{
HIGH SCHOOL REFORM AND BUILDING OUR RESISTANCE \\ IN DEFENSE OF PUBLIC EDUCATION
}

\section{REFORMA DE LA ENSEÑANZA SECUNDARIA Y LA CONSTRUCCIÓN DE NUESTRA RESISTENCIA EN DEFENSA DE LA EDUCACIÓN PÚBLICA}

Domingos Leite Lima Filho ${ }^{1}$

\begin{abstract}
RESUMO
No presente artigo discutimos a reforma do ensino médio, em implementação no Brasil, a partir de 2.017, mediante a Lei n. 13.415, a Base Nacional Comum Curricular e as Diretrizes Curriculares Nacionais do Ensino Médio. O texto consta de uma introdução e dos seguintes tópicos: Regressão e contrarreforma social nos marcos da dependência e subalternidade; A educação pública e o ensino médio no contexto da contrarreforma social: questões de estrutura e conjuntura; $O$ projeto educacional regressivoconservador: educação como mercadoria e mecanismo de adaptação à exclusão social; O projeto social e educacional da classe trabalhadora: formação integral e emancipação humana; Considerações finais: construir a resistência necessária. Argumentamos que a reforma do ensino médio é parte da contrarreforma social para a supressão de direitos sociais no contexto de disputa de projetos que vivemos no Brasil e da forma de inserção subalterna e dependente do país na ordem mundial, o que envolve a adequação da educação, do trabalho e da classe trabalhadora a este projeto.
\end{abstract}

Palavras-chave: Reforma do ensino médio. Lei 13.415. Regressão social. Política educacional. Educação e trabalho.

\begin{abstract}
In this article we discuss the reform of the high school, in implementation in Brazil, from 2.017, through the Law n. 13,415, the Common National Curriculum Base and the National High School Curriculum Guidelines. The text consists of an introduction and the following topics: Regression and social counterreform in the context of dependency and subordination; Public education and high school in the context of social counter-reform: questions of structure and conjuncture; The conservative regressive educational project: education as a commodity and mechanism of adaptation to social exclusion; The social and educational project of the working class: integral formation and human emancipation; Final Considerations: Build the necessary resistance. We argue that high school reform is part of the social counter-reform for the suppression of social rights in the context of disputing projects that we live in Brazil and of the country's subordinate and dependent insertion in the world order, which involves the adequacy of education, from work and working class to this project.
\end{abstract}

Key words: High school reform. Law 13,415. Social regression. Educational politics. Education and work.

\section{RESUMEN}

En este artículo discutimos la reforma de la enseñanza secundaria, en implementación en Brasil, desde 2.017, a través de la Ley n. 13.415, Base Nacional Comum Curriculary Diretrizes Curriculares Nacionais do Ensino Médio. El texto consta de una introducción y los siguientes temas: regresión y contrarreforma social en el marco de la dependencia y la subordinación; Educación pública y enseñanza secundária en el contexto de la contrarreforma social: cuestiones de estructura y coyuntura; El proyecto educativo

\footnotetext{
Universidade Tecnológica Federal do Paraná (UTFPR). Curitiba - PR, Brasil. ORCID https://orcid.org/0000-0003-3802-6794. E-mail: dllimafilho@gmail.com
}

Artigo recebido em setembro de 2019. Aprovado em novembro de 2019. 
regresivo conservador: la educación como mercancía y mecanismo de adaptación a la exclusión social; El proyecto social y educativo de la clase trabajadora: formación integral y emancipación humana; Consideraciones finales: Construir la resistencia necesaria. Argumentamos que la reforma de la enseñanza secundaria es parte de la contrarreforma social para la supresión de los derechos sociales en el contexto de disputa de proyectos que vivimos en Brasil y la forma de inserción subordinada y dependiente del país en el orden mundial, que implica la adecuación de la educación, del trabajo y la clase trabajadora a este proyecto.

Palabras clave: Reforma de la enseñanza secundaria. Ley 13.415. Regresión social. Política educativa. Educación y trabajo.

Privatizado

Privatizaram sua vida, seu trabalho, sua hora de amar e seu direito de pensar

É da empresa o seu passo em frente, seu pão e seu salário.

E agora não contentes querem privatizar o conhecimento, a sabedoria, o pensamento, que só à humanidade pertence.

Bertold Brecht

O poema de Bertold Brecht (2007), na epígrafe deste texto, embora escrito em outras circunstâncias e tempos ${ }^{2}$ e resguardadas as singularidades e particularidades da história, pode ser útil para ilustrar a dureza dos tempos que ora vivemos no Brasil, marcado pela exaltação da economia de mercado, pelo ataque às instituições públicas e à democracia e por duras regressões sociais, consequências imediatas do golpe parlamentar-jurídico-midático de abril de 2016 e de seus desdobramentos. As forças políticas e econômicas que sustentaram o golpe e se aglutinaram na sustentação do atual governo representam uma concentração de interesses políticos e econômicos de matiz conservador e fundamentalista de direita que uniu as classes dominantes e grandes corporações em associação subalterna ao domínio imperialista que caracterizam o contexto social e político regressivo da atual conjuntura.

A regressão social que ora se abate sobre a sociedade brasileira e especialmente sobre a classe trabalhadora se caracteriza e se evidencia, dentre outros aspectos, pelos ataques sistemáticos às instituições públicas, redução e/ou extinção de programas sociais e políticas públicas; ataques produzidos pelas reformas trabalhista e da previdência; ameaças â liberdade de associação e de expressão, ataques à autonomia da universidade pública, dos institutos federais e controle das escolas de educação básica; extinção de conselhos sociais com participação de representantes da sociedade civil, criminalização dos movimentos sociais e populares e perseguição a suas lideranças.

Os objetivos estratégicos deste agrupamento de poder são a dissolução e desmonte das conquistas de políticas públicas e de direitos sociais que ao longo de muitas décadas foram sendo duramente construídos, como as garantias da Constituição de 1988, como as da educação e saúde públicas, ou mesmo de algumas questões básicas dos direitos trabalhistas ainda originários da CLT na década de 1940. Enfim, busca-se a derrogação de marcos civilizatórios alcançados ou em construção pela sociedade brasileira ao longo do século XX, como fruto de lutas sociais da classe trabalhadora, dos movimentos sociais e populares.

Estes retrocessos, que atingem especialmente os trabalhadores e as camadas mais pobres da população brasileira, buscam a submissão total da nação aos desígnios

\footnotetext{
Grande parte da produção literária de Bertold Brecht (1898-1956) deu-se no contexto da ascensão e chegada ao poder do nazismo na Alemanha e de suas terríveis consequências. Naquele contexto, Brecht envolveu-se na construção da resistência social e segundo CITELLI (2007), em sua obra poética, assim como em sua produção teatral, "é perceptível a mesma preocupação com o efeito de estranhamento, traduzida em poemas de alto envolvimento político, desdobrado em temas como a resistência à barbárie, a luta pela justiça social, a denúncia da alienação e o engajamento em acontecimentos sociais. Em uma palavra, segundo a compreensão de Brecht, poesia e revolução social devem caminhar do mesmo lado" (CITELLI, 2007, p. 110).
} 
do mercado e dos interesses das elites conservadoras, a submissão dos governos, do legislativo e do judiciário à acumulação e riqueza privada, a privatização das empresas estatais e de recursos naturais, a apropriação dos fundos públicos, o recrudescimento e manutenção de elitismos e privilégios dos ricos, as exclusões dos pobres, negros, indígenas e trabalhadores, o recrudescimento da homofobia e do machismo, o ataque aos direitos étnico-raciais e de liberdade de gênero e opção sexual. $E$, com esta regressão social, também a tentativa de subordinação da ciência, da tecnologia, da cultura e do trabalho aos interesses meramente mercantis e a manutenção e acirramento da dependência e subalternidade na produção e apropriação do conhecimento.

É nesse entorno e conjuntura que situamos a reforma do ensino médio. Para compreender as razões e objetivos desta reforma, como parte de uma contrarreforma social, na qual se incluem o Programa Future-se, os cortes orçamentários que visam ao sucateamento das universidades públicas, dos institutos federais, do CNPq e da CAPES, é preciso recuar na análise e conectarmos a atual conjuntura com conjunturas passadas e aspectos estruturais da formação e da estrutura social, política e econômica brasileira, da educação e do trabalho.

\section{Regressão e contrarreforma social nos marcos da dependência e subalternidade}

A análise da reforma e das medidas acima citadas, com vistas à apreensão de sua natureza e objetivos, requer situa-las no contexto estrutural e conjuntural que demarca a forma de inserção do Brasil no cenário atual do capitalismo mundial e da divisão internacional do trabalho. Ou seja, para além das reações imediatas e pontuais, é necessário tentar apreender os objetivos estratégicos que se escondem por detrás das faces raivosas e das ações e murmúrios odientos, racistas, homofóbicos, antinação, anticultura e anticiência. Nesse sentido, consideramos que os objetivos estratégicos desta contrarreforma social são os de submeter o país à subalternidade econômica, política, cultural, científica-tecnológica e militar da geopolítica do poder no capitalismo mundial, hegemonizada sobretudo pelos EUA. Para tanto, além do aniquilamento de todo o sistema nacional de produção cultural, científica e tecnológica, visa intensificar o processo de superexploração da classe trabalhadora e abrir todos os espaços possíveis para extração da mais-valia, inclusive e especialmente a privatização, financeirização e transformação de todos os serviços públicos em mercadoria rentável ao capital.

Entretanto, aqui encontram-se os elos que unem passado e presente, estrutura e conjuntura. O Brasil se insere na ordem econômica mundial do capitalismo mercantil, inicialmente pela superexploração do trabalho, na forma do escravismo moderno. $\mathrm{Na}$ sequência, seja na economia agroexportadora, seja na industrialização dependente de importações, na máxima extração da mais-valia da classe trabalhadora, submetida a precárias condições de salário e direitos e a baixos níveis de escolaridade. Nesse quadro, a partir da aristocracia agrária, em parte reconvertida em burguesia industrial e de serviços, mediante associação subalterna ao capital internacional, forma-se uma elite econômica que exerce o patrimonialismo sob o estado e apropria-se privadamente de significativas parcelas dos fundos públicos. Rui Mauro Marini, em A Dialética da dependência, ainda nos anos de 1970, já mostrava esse caráter de subalternidade e de superexploração do trabalho da sociedade brasileira (TRASPADINI; STEDILE, 2005), tese corroborada inclusive por Teotônio dos Santos, no livro Imperialismo y dependencia (SANTOS, 1978).

Francisco de Oliveira, destacou esse processo como o amálgama que produziu uma sociedade desigualitária e monstruosa, à qual ele associou a figura do ornitorrinco, um estranho animal dotado de bico de pato - considerado ao mesmo tempo réptil, pássaro e mamífero - como metáfora do Brasil enquanto nação presa a um impasse evolutivo, para descrever a natureza do "projeto" de sociedade conduzido historicamente pelas elites brasileiras: uma sociedade que se alimenta do atraso e da produção de mais exclusão para seguir existindo nas suas relações de poder e propriedade e garantir transferência do máximo de mais-valia ao capital nacional e internacional (OLIVEIRA, 
2003). Essa subalternidade, essa dependência, associada à superexploração dos trabalhadores, à apropriação privada da renda e da riqueza nacional, produziu ao longo dos tempos um país de enormes e permanentes desigualdades sociais.

E é claro que ao longo de nossa história, apesar das lutas populares e dos trabalhadores, e foram muitas lutas, essa permanência e aprofundamento das desigualdades foi sendo feita e mantida ou pelo discurso dominante, ou pela negociação, ou pelo golpe. $\mathrm{E}$ os golpes promovem os programas de ajuste (leia-se exclusão), regressões ou contrarreformas sociais como, por exemplo, o Golpe de 1964, e como esse que nós estamos atualmente enfrentando. Discursos sobre a necessidade de modernização das relações trabalhistas, da eficiência e eficácia com a administração e os gastos públicos, do combate à corrupção e de fundamentalismo moral e religioso são úteis, em contextos e conjunturas diversas, para encobrir esta reiteração histórica, o que nos remete à análise de Karl Marx sobre os retrocessos sociais de sua época, metade do século XIX, na França, quando escreveu: "A história se repete, como tragédia, ou como farsa" (MARX, 1987).

Das lutas de resistência à ditadura e do acúmulo de forças dos movimentos sociais e populares temos o legado da Constituição Federal de 1988 que, embora limitada em vários aspectos, avançava em relação aos direitos e garantias sociais, cujos desafios subsequentes seriam sua regulamentação em leis ordinárias e complementares e a respectiva implementação em políticas públicas. Após um período de expectativas iniciais, veio o intervalo dos anos de 1990, marcados pelos retrocessos das políticas neoliberais. Entre 2003 e 2014, os governos da Frente Brasil Popular, liderada pelo Partido dos Trabalhadores, em alianças de amplo matiz ideológico da esquerda à direita, apesar de não romperem com os marcos da macroeconomia, buscaram implementar políticas de garantias de direitos sociais, de ampliação dos serviços públicos, de distribuição de renda e de redução das desigualdades sociais, dentre as quais pode-se destacar: elevação real do salário mínimo; fortalecimento da política de seguridade social (SUS, assistência e previdência); combate às formas de superexploração do trabalho, inclusive infantil e escravo; assentamento e titulação de terras para trabalhadores rurais; a garantia dos direitos das comunidades indígenas e quilombolas; a ampliação da educação básica, profissional e superior públicas (veja-se por exemplo o caso da criação dos Institutos Federais e de novas universidades federais e ampliação das existentes); as políticas de cotas e assistência para ingresso e permanência de jovens negros e negras nas escolas e universidades; os direitos da mulher e o reconhecimento e proteção da diversidade de gênero; o fortalecimento da Petrobras (com as reservas estratégicas do pré-sal) e de outras empresas estatais.

As políticas citadas no parágrafo anterior caminham em direção contrária às tendências que predominam no contexto atual do capitalismo global, em que se estabelece o movimento de captura da democracia e da política pelo mercado. Este realinhamento do capitalismo, com a ascensão de uma nova direita em âmbito mundial, movimento do qual a eleição de Donald Trump (EUA) é a maior expressão, impactam o cenário nacional, já marcado pela fragilização das forças populares e democráticas ante o fortalecimento de alianças cada vez mais a direita, levando ao desfecho do impeachment e do Golpe de 2.016.

Com efeito, as sucessivas crises do capitalismo têm acentuado o caráter predatório e deshumanitário do sistema: desemprego global, guerras, perda de valores éticos e de solidariedade, aumento da intolerância e ódio, insegurança, intensificação e precarização do trabalho, golpes de novo formato ou processos de "guerras híbridas" (KORYBKO, 2.018), como os ocorridos na Europa (Ucrânia), Ásia (Síria) e na América Latina (Paraguai, Honduras e Brasil), nos quais os EUA jogam papel preponderante.

Em vez de confrontar diretamente os alvos em seu próprio território, conflitos por procuração serão promovidos na vizinhança dos alvos para desestabilizar sua periferia. As tradicionais ocupações militares podem dar lugar a golpes e operações 
indiretas para troca de regime, que rem um melhor custo-benefício e são menos sensíveis do ponto de vista político (KORYBKO, 2018, p. 12).

Nesse contexto, as relações nacionais e internacionais assumem um aspecto em que cada vez mais a democracia e o poder político de decisão dos cidadãos é capturado pelo poder corporativo do mercado. Ou seja, o domínio da economia sobre a política expressa-se como a dominação do setor privado sobre o setor público e transforma-se em poder político articulado que constitui a nova arquitetura do poder realmente existente. Há um deslocamento radical da política, de atender aos interesses dos cidadãos para servir ao mercado:

\begin{abstract}
cada vez mais o governo tem de prestar contas ao mercado, e virar as costas para a cidadania. Com isso, passa a prevalecer, para a sobrevivência de um governo, não quando ele responde aos interesses da população que o elegeu, e sim se o mercado, ou seja, essencialmente os interesses financeiros [das grandes corporações] se sentem suficientemente satisfeitos para declara-lo confiável (STREEK, 2014, p. 81).
\end{abstract}

A mensagem principal de Buying Time: the delayed crisis of democratic capitalism (STREEK, 2014) é que os tempos presentes indicam os riscos da evolução para um capitalismo em que a democracia, mesmo nos aspectos formais, seria dispensável. Este autor, mediante um interessante quadro comparativo, traça um paralelo entre características de dois tipos de Estado: o Estado cidadão (no qual temos a res pública) e o Estado Corporativo (em que temos a res mercatori). No Estado orientado pela res publica o foco seriam os cidadãos, no orientado pela res mercatori o foco seriam os investidores. Dicotomias semelhantes são as que colocam nos dois tipos de Estado direitos civis $x$ direitos contratuais; eleitores $x$ credores; eleições periódicas $x$ leilões contínuos; opinião pública x taxa de juros; lealdade para com os cidadãos x "confiança" ante os investidores; realização dos serviços públicos $x$ pagamento dos serviços da dívida.

As consequências desta captura e ressignificação são o crescimento das desigualdades dentro e entre as nações em todo o mundo e o travamento da produção social pelo desvio para a acumulação do capital financeiro. Outro aspecto fundamental é a ampliação dos mecanismos de extração de mais-valia para todas as esferas da vida social, o que inclui a prestação dos serviços básicos (saúde, educação, transportes, moradia, saneamento, segurança), como também a infraestrutura do Estado. Nesta lógica, que é a arquitetura do neoliberalismo, os direitos sociais são convertidos em mercadoria e o Estado assume a feição empresarial. Não se trata somente de privatizar o público, mas do próprio estado transformar-se em empresa. No seio do estado empresarial, a educação é mercadoria, e não somente as escolas, institutos, universidades são organizados e funcionam como empresas, maximizando os seus resultados, mas também os sujeitos da educação (professores, técnicos educacionais e estudantes) são orientados a atuar como empresa, pautando suas ações pela racionalidade da competitividade e do máximo retorno de seu "capital humano" (DARDOT e LAVAL, 2016).

No contexto do golpe e de seus desdobramentos, as políticas públicas de caráter social vão sendo atacadas e desmontadas e estão sendo substituídas por políticas contrárias e regressivas, de caráter privatista e mercadológico. Para uma análise mais contextualizada da natureza e objetivos das orientações que norteiam as políticas conduzidas pelo golpe em curso é útil a leitura de alguns documentos, dentre os quais destacam-se o documento "Uma Ponte para o Futuro" (FUNDAÇÃO ULYSSES GUIMARÃES, 2015), a Emenda Constitucional n. 95 (BRASIL, 2016) e o Relatório "Um Ajuste Justo" (BANCO MUNDIAL, 2017). Ali estão, em detalhes e no atacado, menções diretas ou indiretas às medidas que estão sendo anunciadas ou já em implementação.

Nesse sentido, argumentados que a razão do golpe e das reformas que acontecem em seus desdobramentos é barrar conquistas sociais, realizar a apropriação privada 
das riquezas naturais e dos fundos públicos e garantir condições para elevação das taxas de extração de mais valia e apropriação privada da produção social. Em síntese, o golpe e seu programa é um processo restaurador e recrudescimento do neoliberalismo no país, tanto no plano do alinhamento subalterno e dependência internacional, quanto na regressão das políticas sociais. As iniciativas e ações particulares em cada campo específico compõem um conjunto que pode ser claramente caracterizado com uma contrarreforma social.

E quais são os impactos deste programa restaurador para a educação? Nessa direção, argumentamos que a reforma do ensino médio e a reforma da universidade (caracterizada pelo Programa Future-se) constituem, em conjunto, uma contrarreforma educacional, como parte de um movimento de recomposição da hegemonia, privilégios e tradições das elites dominantes e de sua associação subordinada ao capitalismo dos países centrais, notadamente aos interesses dos EUA(vale lembrar que o golpe no Brasil também pode e deve ser analisado num quadro de golpes contra governos de esquerda e centro-esquerda na América Latina e Caribe). Hegemonia que poderia ser fragilizada caso se mantivessem políticas orientadas para a ampliação dos direitos sociais dos trabalhadores e das camadas mais pobres e excluídas da população. Hegemonia, privilégios e tradições que se assentam historicamente na superexploração do trabalho, no patrimonialismo sobre o Estado e em reiterações de manutenção de resquícios da herança escravocrata. Nessa direção estão conectados os principais objetivos do Future-se e da Reforma do Ensino Médio: a desresponsabilização do Estado com o financiamento da educação pública e a privatização, via transferência dos fundos ou do próprio patrimônio público para a iniciativa privada, ou seja, elitização, mercadorização e financeirização da educação.

\section{A educação pública e o ensino médio no contexto da contrarreforma social: questões de estrutura e conjuntura}

Nossa crítica e caracterização da reforma do ensino médio como regressiva não implica entender que o ensino médio brasileiro, tal como se encontra na atualidade, atende plenamente aos interesses da maioria da população, sobretudo, aos interesses da classe trabalhadora e não necessitaria de mudanças. Em artigos anteriores de MOURA, LIMA FILHO e SILVA (2015) e MOURA e LIMA FILHO (2017) foram apontados, nessa perspectiva, grandes desafios e problemas que que precisam ser enfrentados e solucionados pela pública educacional brasileira.

Assim, olhando para a questão do ensino médio, nosso ponto de partida é a realidade concreta: Qual a real situação do ensino médio brasileiro na atualidade? Quais os desafios e problemas a enfrentar? O que queremos da educação para a população, o que queremos nós educadores e professores, para os nossos estudantes, para a nação? A reforma proposta pela Lei 13.415, BNCC e diretrizes curriculares pretende enfrentar esta realidade e desafios?

\footnotetext{
Superar o fenomênico e aproximar-se do real concreto exige, de princípio, a consideração de que as reformas passadas ou atuais, constituem-se sobre uma base histórica de relações sociais de poder. O desafio da pesquisa segue sendo, portanto, o de perquirir a realidade, tentando recompor na teoria a trama histórica que dá vida ao objeto investigado (LIMA FILHO, 2018, p. 686).
}

Nesse sentido, destacam-se dois desafios que inclusive se apoiam na garantia constitucional do direito subjetivo à educação. O primeiro deles é o DIREITO UNIVERSAL AO ENSINO MÉDIO, o que implica necessariamente políticas de ampliação e universalização da oferta nesta etapa educacional, com condições que garantam suporte de condições aos estudantes para a permanência e conclusão. $O$ segundo é a QUALIDADE SOCIALMENTE REFERENCIADA DO ENSINO MÉDIO, o que implica políticas que garantam as condições de funcionamento das escolas 
públicas, compreendendo a totalidade das infraestruturas físicas, dos recursos didáticopedagógicos e das condições de trabalho e carreira dos profissionais da educação.

Um terceiro desafio, imbricado aos dois já citados, é o de situar o projeto educacional no contexto de um projeto societário. Nesse sentido, o desafio é um ENSINO MÉDIO VOLTADO PARA A CONSTRUÇÃO E CONSOLIDAÇÃO DE UMA SOCIEDADE DEMOCRÁTICA. Nesse sentido, cabem as perguntas: Qual a perspectiva (concepção, políticas e práticas) de formação dos adolescentes e jovens que traz a Reforma do Ensino Médio (Lei 13.415, Base Nacional Comum Curricular e Diretrizes Curriculares Nacionais)? Qual a relação dessas concepções com o trabalho e com a formação dos trabalhadores? Enfim, qual a relação dessas concepções com um projeto de sociedade? Qual projeto de sociedade para o Brasil?

Estas perguntas só podem ser enfrentadas se buscarmos entender a disputa de projetos que historicamente marca a sociedade brasileira. Para compreender a realidade, nós precisamos compreender essa realidade não somente no seu momento, mas também no seu percurso e na sua persistência histórica, na estrutura que permeia a dominação de classes na sociedade brasileira. E a sociedade brasileira é uma sociedade que se insere no mundo capitalista, mas que tem as suas particularidades históricas de formação social. Portanto, precisamos considerar a estrutura e a conjuntura em que se situam a reforma educacional, nas quais a reforma ganha significado e sentido. Ou seja, faz-se necessário observar a TOTALIDADE das relações sociais (trabalho, cultura, poder, linguagem ...) e dentro desta totalidade, ver a educação; considerar a HISTORICIDADE destas relações, os momentos passados, o presente, etc; e, identificar os SUJEITOS sociais e seus diversos interesses.

Tendo em conta estas três categorias, uma análise da educação no Brasil deve necessariamente considerar dois fatores históricos marcantes de nossa formação social, todavia presentes na atualidade, o colonialismo e o escravismo moderno, dos quais a burguesia e elites do país serviram-se para marcar sua própria configuração e atuação no controle do Estado e da economia. Estes fatores igualmente compõem a forma de inserção do país no cenário internacional, como país subalterno e dependente. Nesse sentido, autores como Caio Prado Júnior asseveram que seria demasiado usar a expressão burguesia nacional, uma vez que as elites brasileiras nunca tiveram efetivamente um projeto de nação, no qual soberania, autonomia e independência se pusessem como valores inegociáveis. Ao contrário, reiteradamente ao longo da história, estes valores sociais foram objetos de negócio, na relação das elites com o capitalismo central.

Não é necessário aprofundar que o colonialismo se reflete diretamente na produção de ciência e tecnologia, na produção cultural, no tipo e qualidade dos trabalhos e empregos ... e, portanto, na educação. No que se refere ao escravismo moderno, é necessário destacar a persistência da herança escravocrata, especialmente sobre o trabalho, atividade dos escravizados na origem da formação social brasileira, e, portanto, associando-se à esta marca histórica de negatividade, temos a permanência do desvalor social do trabalho, sobretudo do dito trabalho manual, não do intelectual. Mas, este desvalor social do trabalho, dará origem à desvalorização (redução dos currículos e dos conteúdos) da educação para os que trabalham (vale dizer, fundamentalmente os que frequentam e dependem da escola pública), das próprias instituições e redes educacionais públicas e, corolário, dos profissionais que atuam nestas redes. ${ }^{3}$

Estas duas marcas históricas, a dependência/subalternidade nacional e desvalor social do trabalho, apoiam e realimentam a máxima extração da mais-valia que caracteriza também a economia brasileira. Embora não expliquem tudo, condicionam fortemente a constituição de uma sociedade desigualitária, de uma classe trabalhadora submetida a precárias condições de salário e direitos e a baixos níveis de escolaridade. No âmbito das concepções, políticas e programas educacionais esta hegemonia se expressa na configuração de uma marca característica: a dualidade educacional.

3 A este respeito ver CUNHA (2000a, 2000b, 2000c). 
Neste sentido, podemos interpretar o ataque à educação pública, tanto a básica quanto a superior, como um objetivo interligado ao intento de reafirmação da dualidade educacional, posto que a ampliação das redes públicas de qualidade (veja-se por exemplo, a ampliação da oferta do ensino médio, das universidades públicas e dos institutos federais, e sua capilarização para cidades interioranas) efetivamente significam oportunidades de elevação da qualidade educacional para a classe trabalhadora, portanto em direção contrária à dualidade educacional.

Decorrente dessa análise da reiteração constatamos que a sociedade brasileira apresenta histórico déficit civilizatório (cultural, científico, técnico) no que diz respeito à educação da classe trabalhadora e das camadas populares (universalidade do atendimento, níveis de formação e extensão e profundidade dos conteúdos). É déficit civilizatório, porque a política pública não cumpre a universalidade para o atendimento dos direitos educacionais plenos para todos e em todos os níveis. É déficit civilizatório pela redução das áreas do conhecimento, pela subtração dos conteúdos da ciência, tecnologia, cultura e artes, pela inviabilização da qualidade das infraestruturas materiais e de carreiras, condições de trabalho e salários dos profissionais da educação pública.

Vemos que este viés persiste na atual reforma proposta para o ensino médio e para a educação profissional. Conhecer este viés é importante para a gente entender como esses argumentos são reiterados nas reformas e contrarreformas que se sucedem e afetam especialmente a escola pública. Pois, claro, para os que frequentam a escola privada, não há problema que exista uma orientação minimalista e restrita de formação. Isso tem pouco efeito na escola privada, pois elas, em reformas anteriores seguiram e nesta reforma é muito provável que seguirão praticando o seu currículo mais amplo e geral, mas, ao contrário, para a escola pública o reducionismo da reforma tem força determinante, com efeitos imediatos e mediatos de precarização e sucateamento.

Então, é claro, não podemos compreender o sentido das reformas educacionais somente pela análise do currículo, da política de formação dos professores ou da infraestrutura, embora estas sejam dimensões centrais da análise. Mas, é necessário ver o conjunto social e a história. Todo projeto educacional, tem por base um projeto societário. E, em uma sociedade dividida em classes, de interesses antagônicos, todo projeto educacional e pedagógico, também carrega consigo um projeto de hegemonia social. Ou seja, nosso desafio é de apreender a totalidade: necessário entender a reforma do Ensino Médio no contexto específico da análise de seus elementos próprios (Lei 13.415, Base Nacional Comum Curricular e Diretrizes Curriculares Nacionais do Ensino Médio); mas, necessário igualmente entender a reforma como parte de uma contrarreforma para a supressão de direitos sociais no contexto de disputa de projetos que vivemos no Brasil e da forma de inserção do país na ordem mundial, o que envolve a adequação da educação, do trabalho e da classe trabalhadora a este projeto.

\footnotetext{
Para além desses discursos de natureza ideológica que se situam no mero aspecto fenomênico da discussão e embates em torno do EM, o que fundamentalmente se disputa na essência dessa questão é: 1) De um lado, a operacionalidade dos sistemas educacionais, sua funcionalização às demandas imediatas do capital e a adequação da reprodução da força de trabalho ao processo de valorização do capital (o que faz e como faz no imediato da atividade de produção); 2) De outro lado, a subjetividade do trabalhador e do cidadão (o que deve pensar, como deve se reconhecer, seus valores, nas relações de mediação no trabalho e entre este e outras dimensões da sociabilidade) (MOURA e LIMA FILHO, 2016, p. 182).
}

No quadro das reformas, apoiadas no neoliberalismo e na acumulação flexível, as ideias e palavras chave são ressignificadas em seu sentido e conteúdo: o elegante nome de reestruturação produtiva, corresponde de fato à intensificação da extração de mais-valia; desregulamentação é um nome interessante para encobrir a quebra de direitos sociais; austeridade é o cognome que encobre a redução ou extinção de políticas sociais; flexibilização é o pseudônimo da adaptação passiva e captura da subjetividade dos trabalhadores; eficiência, eficácia e competitividade são os elogiosos desígnios 
usados para ensejar a privatização do patrimônio e a transferência dos fundos públicos aos interesses privados e aos grupos empresariais internos e externos.

Resultantes do aprofundamento e desdobramentos do golpe midiático-parlamentarjudiciário e das elites econômicas perpetrado em 2016, a reforma do ensino médio e a reforma da universidade, assim como as reformas trabalhista e da previdência, retomam uma herança colonial e de resquícios da ordem escravocrata que se atualizam e se reproduzem de modo ampliado sob novas formas de dominação, colonização e subalternidade cultural, científica e tecnológica. Um modelo em que se aprofunda da desigualdade social e dela se realimenta, onde a democracia formal torna-se a cada dia mais restrita e o clientelismo e patrimonialismo das elites se exacerba.

Conforme Saviani (2007), a educação, na perspectiva da emancipação humana, busca realizar em cada sujeito das novas gerações o legado de conhecimentos produzidos e acumulados historicamente pela humanidade. Ora, isso implica, consideradas as diversas faixas etárias e níveis escolares concernentes, um esforço e compromisso social e institucional que permita a apreensão dos conhecimentos linguísticos, científicos, tecnológicos, artísticos, das habilidades e práticas do trabalho, dos valores culturais e ético-políticos. É um processo de transmissão, aquisição e apropriação dos conhecimentos com vistas à formação integral dos sujeitos, portanto, processo de transformação, mas também de autotransformação. Autotransformação intelectual, cultural e moral que é a base para compreender a sociedade vigente e o seu papel nela, é portanto, um processo de produção de si e do todo, um percurso para a autonomia e para a construção da coletividade, uma apropriação teórico-prática da vida para produzir a existência, para dirigir a produção e para controlar quem dirige (GRAMSCI, 1979).

Por isso, a educação de qualidade, socialmente referenciada é estratégica para um projeto de sociedade, especialmente para os que pensam uma sociedade que supere as contradições da alienação capitalista. Situadas estas questões, as perguntas que nos interpelam, para a apreensão do sentido e significado das atuais políticas educacionais no Brasil e, em particular, da reforma do ensino médio e do Future-se que compõem o ataque aos IFs e universidades públicas, são:

- Quais são as bases conceituais e operacionais que norteiam o as reformas em curso?

- Quais são as bases de um projeto educacional contra hegemônico e suas possibilidades, limites e desafios no contexto atual?

- Quais são as bases principais da construção de nossa resistência a estes ataques que se conectam com a privatização e desresponsabilização do Estado com a educação pública de qualidade?

\section{O projeto educacional regressivo-conservador: educação como mercadoria e mecanismo de adaptação à exclusão social}

A educação também passa a ter um léxico reformista próprio, como subsidiária do neoliberalismo e da acumulação flexível. Os conceitos de competência, gestão empresarial, empreendedorismo e competitividade, (todos tendo o mundo empresarial como modelo, são elementos fortes desta nova roupagem da pedagogia do capital trazida nas concepções que compõem a reforma do ensino médio. Não temos aqui espaço para desenvolver a apresentação e a crítica a cada um deles, no entanto, destacamos que a reforma do Ensino Médio, orientada por tais concepções, pode ser melhor entendida como um movimento de luta pela hegemonia no campo educacional defendido pelos setores conservadores contra as posições críticas e questionadoras.

Arespeito da pedagogia das competências é importante compreender dois aspectos: primeiro, ela propõe substituir o domínio dos conhecimentos, pela valorização da prática, ou seja, pelo pragmatismo da aplicação de fragmentos de conteúdos para a resolução 
de problemas do cotidiano: os alunos são treinados para desenvolver competências cognitivas para solucionar problemas práticos, é a subsunção do processo educacional ao pragmatismo utilitarista para resolver problemas concretos (do capital); segundo, os estudantes devem também desenvolver as competências sócio-emocionais (atitudes e habilidades) os seja, ser funcionais, resilientes, proativos e colaboradores. Enfim, que tenham a sua subjetividade capturada e adaptada ao processo de flexibilização dos direitos da acumulação flexível. Jamais cidadãos críticos, trabalhadores contestadores.

As práticas da "boa gestão", por sua vez, se conectam ao processo de financeirização da educação básica. Para materializar tais práticas nas escolas é incentivado e estabelecido o custeio público para a contratação de consultores empresariais (veja-se todo o trabalho das chamadas fundações e reformadores empresariais da educação). Com o avanço da concepção de educação como mercadoria tem lugar um processo de educação para o mercado (enquanto conteúdo e práticas educacionais), acrescido de uma abertura de educação pelo mercado (educação básica como atividade lucrativa para empresas e grandes cartéis), com todo um conjunto de compra e venda de mercadorias: sistemas de gestão, pacotes de avaliação e formação, materiais e equipamentos didáticos e inclusive as próprias escolas. Assim, aspira-se converter tudo na educação à condição de mercadoria: aos que podem pagar pelo consumo muito bem, aos outros ... ora, aos outros! Veja-se que a BNCC do ensino fundamental e do ensino médio e própria Lei 13.415, na medida que ampliam as possibilidades de execução de grande parte do currículo por parcerias e por Educação a Distância facilitam a mercadorização, com a disponibilização dos recursos do FUNDEB para empresários da educação em vários campos.

Quanto ao empreendedorismo, em linhas anteriores deste texto já comentamos seu matiz vinculado ao ideário do capital. No que se refere à orientação para a competitividade, busca-se uma educação a serviço do capital, para a ordem, para a conformação, não para a transformação. Ora, se se trata de formar pessoas para o capital, também as pessoas são transformadas em coisas, em mercadorias que se vendem e competem umas contra as outras. Perde-se o sentido de coletividade, de solidariedade e da educação como formação para a emancipação humana e entra em cena o indivíduo produtivo e competitivo para a apropriação privada para si e para a empresa.

No caso da reforma do ensino médio vejamos, sinteticamente, a articulação dos conceitos: a BNCC proposta só com Língua Portuguesa. Matemática e Inglês como disciplinas obrigatórias é extremamente pobre e reducionista; a realização de grande parte do ensino médio a distância e por parcerias (EAD) abre flanco total para a mercadorização; os itinerários fragmentados, com orientação para a saída precoce ao mercado induzem o chamado empreendedorismo; a centralização dos objetivos e conteúdos em torno dos indicadores de avaliação, cuja referência é o PISA, mostra o direcionamento para a competição e competitividade.

E qual é a questão central que unifica estes conceitos no projeto educacional regressivo-conservador? É a renúncia de um sonho de um futuro diferente para esses jovens que estão no ensino médio e estes jovens e adultos que estão frequentando a educação profissional e a educação de jovens e adultos. A adequação proposta pela contrarreforma social e pela reforma do ensino médio é uma redução ontológica, é uma redução do ser. Dizem os reformadores empresariais e golpistas: um currículo atual e enxuto, rápido, operacional. Não precisamos forma-los na integralidade, nas artes, na cultura da ciência, precisamos de um ser adaptável, flexível e a serviço do capital. Esse é o mote da Reforma! Formar um ser reduzido operacional, antes de formar, eu diria, conformar, deformar! 


\section{O projeto social e educacional da classe trabalhadora: formação integral e emancipação humana}

Vimos que a reforma em curso não toca nos principais problemas do ensino médio, os quais apontamos no início: a universalização e a qualidade socialmente referenciada. As orientações dos currículos e dos itinerários formativos trazidas pela Base Nacional Comum Curricular e pela Lei 13.415 tornam-se questões vazias e abstratas, pois passam longe de enfrentar estes desafios. O problema central do Ensino Médio e da educação pública brasileira está nas condições concretas de funcionamento das escolas e do sistema educacional: infraestrutura dos prédios, existência e funcionamento de laboratórios, de bibliotecas, de quadras esportivas, de cantinas e refeitórios, de salas de trabalhos para os professores; plano de carreira e salários dignos para os professores, formação continuada, jornada de trabalho digna e condições de permanência para a realização da jornada em uma mesma escola. É frequente que os professores precisem se deslocar por mais de uma, as vezes até quatro escolas para cumprir sua jornada, ou compartilhar mais de um vínculo de trabalho para ter uma remuneração que minimamente Ihes garanta a sobrevivência.

Enfim, estas são questões essenciais, e elas sequer são mencionadas. Aliás, é um quadro superficial e discurso vazio, porque se falar em reformar, em melhorar a qualidade das escolas e da educação, e ao mesmo tempo, pelos mesmos golpistas, aprovar-se a Emenda Constitucional 95, que impede por vinte anos o investimento em políticas públicas, como a educação e a saúde, por exemplo, é dizer que de melhora nada será feito. Não dizemos ser contraditório, pois a lógica real que preside a reforma, implícita por detrás dos discursos oficiais explicitados de protagonismo juvenil e da busca de atualidade, eficiência e eficácia para o sistema educacional, é o desmonte da escola pública como espaço de formação humana integral.

Tudo o que é proposto na reforma educacional em curso vai em sentido contrário a uma concepção de educação básica, incluindo aí a educação profissional técnica de nível médio, que trabalha com a concepção de formação humana integral. Então, a reforma não é absolutamente um desconhecimento da realidade ou descontrole dos reformadores: é movimento de recomposição do projeto de hegemonia do modelo societário de exclusão social. Hegemonia que só poderá ser quebrada com muita luta, onde muitas batalhas são travadas), não é enfrentamento conjuntural, é estrutural, luta permanente e radical. E, como disse certa vez Lenin, em meados de 1917, a radicalidade das circunstâncias exige, dos que querem a transformação, a adoção de posições radicais (LENIN, 1983).

Por tudo isso, é necessário resistir a esta reforma. Mas, também apresentar as bases de um projeto educacional ancorado em um projeto social da classe trabalhadora. Nas bases conceituais epistemológicas desse projeto educacional e social se defende a formação humana integral, no seu sentido lato, com acesso ao universo de saberes e conhecimentos científicos-tecnológicos, artístico-culturais e sócio-históricos produzidos pela humanidade, que permitem compreender o mundo, compreender-se no mundo e nele atuar na busca de melhoria das próprias condições de vida e da construção de uma sociedade socialmente justa.

Nesta concepção educacional afirma-se a importância da totalidade, historicidade e integração dos conhecimentos, de sua compreensão como unidade, quebrando falsas dicotomias como as que se referem ao geral e ao específico, bem como a integração entre agir e conhecer, entre teoria e prática. É, portanto, um projeto educacional, mas também social, no sentido ético-político da democracia plena, um projeto educacional e societário efetivamente comprometido com a emancipação humana.

É um projeto social e educacional que está poiado em experiências históricas da humanidade: na experiência republicana, que reconhece a coisa pública, o espaço público e os direitos sociais e nela a educação a ser defendida e praticada é pública, universal, gratuita e laica, plena para todos como direito subjetivo, em todos os níveis 
e modalidades; e também, na experiência da classe trabalhadora, que reconhece o trabalho como fonte da produção material e intelectual da vida.

Quem nos dá esta herança filosófica, pedagógica e social é o materialismo histórico e dialético. Concepções e experiências históricas nas quais se baseiam esta concepção de projeto educacional e social são as proposições da Escola Unitária fundada no trabalho como princípio educativo, com formulações originadas em Marx e Engels e ulteriormente desenvolvidas por Gramsci. Também têm como subsídios a Educação Politécnica, na experiência das escolas-comunas da pedagogia socialista, com referência nas obras de Pistrak e Shulgin, dentre outros.

Reconhecemos que o Ensino Médio atual, cujo caráter predominante é pretensamente propedêutico, não concretiza a formação integral dos sujeitos, limitando as possibilidades de uma efetiva participação social, política, econômica e cultural e comprometendo a inserção qualificada no mundo do trabalho e a continuidade de estudos.

Por isso, argumentamos a favor de um Ensino Médio fundamentado na concepção de formação humana integral, omnilateral, politécnica, tendo como eixo estruturante o trabalho, a ciência, a tecnologia e a cultura, e que tenha sua centralidade na relação entre seus sujeitos e os conhecimentos.

A proposta de ensino médio que defendemos para a atual sociedade brasileira leva em conta a diversidade de situações em que se encontra nossa juventude, especialmente ante a situação do ingresso no mundo do trabalho. Assim, concordamos com Frigotto, Ciavatta e Ramos (2005), quando problematizam a necessidade de profissionalização no Ensino Médio brasileiro. Para os autores,

\begin{abstract}
Se a preparação profissional no Ensino Médio é uma imposição da realidade, admitir legalmente essa necessidade é um problema ético. Não obstante, se o que se persegue não é somente atender a essa necessidade mas mudar as condições em que ela se constitui, é também uma obrigação ética e política, garantir que o EM se desenvolva sobre uma base unitária para todos. Portanto, o EM integrado ao ensino técnico, sob uma base unitária de formação geral, é uma condição necessária para se fazer a "travessia" para uma nova realidade (FRIGOTTO; CIAVATTA; RAMOS, 2005, p.43).
\end{abstract}

Evidentemente, essa travessia para uma nova realidade, a que se referem os autores é a construção de uma sociedade futura, que supere a separação entre trabalho intelectual e trabalho manual e em que se realize efetivamente a emancipação humana. No percurso dessa travessia há duas formas de organizar o Ensino médio: "Ensino Médio Politécnico" e "Ensino Médio Politécnico Integrado à Educação Profissional". Consideramos que ambas são coerentes e poderão coexistir até que as condições objetivas da sociedade brasileira sejam tais que permitam aos jovens da classe trabalhadora concluírem a educação básica por volta dos 17 ou 18 anos de idade sem a obrigação de terem que trabalhar até então. Afinal, esse já é um direito garantido aos filhos dos estratos médio e alto da população desde sempre, inclusive, muitos só começam a trabalhar após a conclusão do ensino superior. Experiências práticas nestas duas possibilidades já estão em curso na sociedade brasileira, desde 2004 com o "Ensino Médio Integrado à Educação Profissional" nos CEFETs (e depois nos IFs), em algumas redes estaduais, como a do Paraná e a da Bahia, ou ainda a Escola Politécnica de Saúde Joaquim Venâncio. Na modalidade de "Ensino Médio Politécnico", temos, a partir de 2011, a experiência da Rede Estadual do Rio Grande do Sul. É fundamental o estudo e socialização do conhecimento destas experiências, verificando suas potencialidades e conquistas, dificuldades e obstáculos. Também podemos nos referenciar na rica experiência do PROEJA (Programa Nacional de Ensino Médio Integrado a Educação Profissional na Modalidade Educação de Jovens e Adultos), seja no âmbito da dos CEFETs e IFs ou em algumas redes estaduais. Com estas experiências podemos aprender muito. 
Aqui se coloca centralmente à questão dos IFs, dos CEFETs, enfim da Rede Federal de Educação Profissional e Tecnológica - RFEPT e da realização do Ensino Médio Integrado também nas redes estaduais. Depois de um período de considerável expansão da rede (infraestrutura, descentralização geográfica-regional, atendimento por cotas, políticas de assistência e permanência, que permitiram a ampliação do acesso, permanência e conclusão, ocorridos nos governos Lula e Dilma, temos agora a regressão que vem sendo conduzida pelos golpistas com as medidas em curso estabelecidas pelo Ministério da Educação, que não só interromperam a expansão, como ameaçam e fecham campis e unidades da RFEPT, além de encerrar programas substancialmente importantes, como o Brasil Profissionalizado, que apoiava a expansão das redes estaduais e o PROEJA, que ampliava e qualificava o atendimento aos jovens e adultos trabalhadores.

Estas experiências se comprovaram positivas e exitosas, não apenas do ponto de vista conceitual, mas também em sua materialização nos IFs, CEFETs e algumas redes estaduais: ainda que considerando nossa crítica aos parâmetros do PISA e outros indicadores de avaliação nacionais, pois eles, além de centrados na competição, não expressam a riqueza e a complexidade do processo educacional, nós não podemos desconhecer os resultados obtidos pelos estudantes do ensino médio integrado feito nos IFs e em algumas escolas da rede públicas estaduais, com valores muito acima das médias nacionais. E o Governo simplesmente desconsidera ou finge desconhecer estes índices, buscando joga-los para baixo do tapete.

Esta análise nos mostra, em síntese, que a rede federal de CEFETs e IFs, as redes estaduais de escolas públicas e as universidades públicas, pela qualidade social da educação ali praticada voltada a formação integral e na perspectiva de uma travessia para uma sociedade efetivamente comprometida com a emancipação humana, são locais estratégicos de nossa resistência necessária. É contra esta perspectiva histórica e contra esta experiência em andamento que vem a proposta de desmonte do governo golpista.

\section{Considerações finais: construir a resistência necessária}

Para nós a resistência às reformas é o imperativo do momento. A resistência da classe trabalhadora, dos pobres e oprimidos contra o capital é estrutural, é histórica e está em todos os momentos e espaços. Mas, sobretudo, neste momento em que a sociedade brasileira vive um processo de regressão e em síntese um estado de exceção, com o aprofundamento da exclusão, a resistência é a palavra-chave.

Em oposição a tudo isto devemos firmar a resistência, mas ir além dela, reafirmar nossa proposta de educação integral e integrada e os princípios fundamentais da educação e da prática democrática calcada em alguns princípios que consideramos fundamentais, dentre eles:

- o caráter universal, obrigatório, público, gratuito e laico da educação com vista à construção e fortalecimento da emancipação social e da cidadania crítica;

- o compromisso com a formação integral humanista de nossos alunos e ao seu respeito como sujeitos de direitos;

- a resistência à pedagogia das competências, ao currículo único e uniforme como base para uma escola "competente e eficaz" para o mercado;

- a resistência à privatização, mercadorização e financeirização da educação;

- a resistência à redução da educação à mera preparação de indivíduos como força de trabalho e recursos humanos para o mercado;

- a resistência à despolitização da educação enquanto prática social;

- a conscientização permanente dos professores e estimulo permanente ao trabalho coletivo, resistindo ao individualismo e à premiação por resultados. 
Enfim, nessa resistência as redes públicas de educação básica e as universidades públicas são estratégicas. São estratégicas não somente porque estão sendo atacadas, sim, também, estão sendo atacadas na perspectiva do seu encolhimento. Mas são estratégicas justamente porque aqui se semeia a semente da esperança, da construção de uma nova sociedade, em que se defende uma sociedade de liberdade, de criação, onde o conhecimento não está separado da arte e onde a arte não está separada da luta.

\section{REFERÊNCIAS}

BANCO MUNDIAL. Um ajuste justo: análise da eficiência e equidade do gasto público no Brasil. Brasília, World Bank, 2017.

BRASIL. Emenda Constitucional, n. 95, de 2016. Altera o Ato das Disposições Constitucionais Transitórias, para instituir o Novo Regime Fiscal, e dá outras providências. Brasília. Disponível em: https://www2.camara.leg.br/legin/fed/emecon/2016/emendaconstitucional-95-15dezembro-2016-784029-publicacaooriginal-151558-pl.html

BRASIL. Lei $n^{\circ} 13.415$, de 16 de fevereiro de 2017. Altera as Leis nos 9.394, de 20 de dezembro de 1996, que estabelece as diretrizes e bases da educação nacional. D.O.U., Brasília, 2017.

BRASIL. Ministério da Educação. Base Nacional Comum Curricular. Brasília, 2015.

BRECHT, B. Privatizando. In A. Citelli. Bertold Brecht: comunicação, poesia e revolução. Comunicação \& Educação. [online].12(2), 109-112, 2007. Recuperado em 24 de abril de 2011, de http://www.revistasusp.sibi.usp.br/scielo.php?pid=S0104-8292007000200013\&script=sci_ arttext\#nt04

CUNHA, L. A. O ensino de ofícios artesanais e manufatureiros no Brasil escravocrata. São Paulo, Brasília, Editora UNESP, FLACSO, 2000a.

CUNHA, L. A. O ensino de ofícios nos primórdios da industrialização. São Paulo, Brasília, Editora UNESP, FLACSO, 2000b.

CUNHA, L. A. O ensino profissional na irradiação do industrialismo. São Paulo, Brasília, Editora UNESP, FLACSO, 2000c.

FERNANDES, F. A Revolução Burguesa no Brasil: um ensaio de interpretação sociológica. Rio de Janeiro, Zahar, 1981.

FRIGOTTO, G.; CIAVATTA, M. \& RAMOS, M. (Orgs.) Ensino Médio Integrado: concepção e contradições. São Paulo, Cortez, 2005.

FUNDAÇÃO ULYSSES GUIMARÃES. Uma ponte para o futuro. Brasília, 2015. Disponível em: https://www.fundacaoulysses.org.br/wp-content/uploads/2016/11/UMA-PONTEPARA-O-FUTURO.pdf

GRAMSCI, A. Os Intelectuais e a Organização da Cultura. Rio de Janeiro, Civilização Brasileira, 1979.

KORYBKO, A. Guerras híbridas: das revoluções coloridas aos golpes. São Paulo, Expressão Popular, 2018.

LENIN, V. I. Obras completas. Moscou, Editorial Progreso, 1983. 
LIMA FILHO, D. L. Contribution to the analysis of educational reforms: theory and ideology under the hegemony of the neoliberal State. Sociology International Journal. , v.2, p.682 - 687, 2018.

MARX, K. O 18 Brumário de Louis Bonaparte. São Paulo, Centauro Editora, 1987.

MOURA, D. H.; LIMA FILHO, D. L. A reforma do ensino médio: Regressão de direitos sociais. RETRATOS DA ESCOLA, v.11, p.109 - 130, 2017.

MOURA, D. H.; LIMA FILHO, D. L. Os diferentes e desiguais ensinos médios no Brasil: o que fazem os que trabalham durante esta etapa educacional In: Produção do conhecimento na pós-graduação em educação no nordeste do Brasil: realidades e possibilidades.1 ed, Teresina: EDUFPI, 2016, v.1, p. 151-187.

MOURA, D. H.; LIMA FILHO, D. L.; SILVA, M. R. Politecnia e formação integrada: confrontos conceituais, projetos políticos e contradições históricas da educação brasileira. Revista Brasileira de Educação, v.20, p.1057 - 1080, 2015.

OLIVEIRA, F. de. Crítica à Razão Dualista: o ornitorrinco. São Paulo, Boitempo, 2003.

PRADO JR., C. A Revolução Brasileira. São Paulo, Brasiliense, 1966.

SANTOS, T. Imperialismo y dependencia. México, Era, 1978.

SAVIANI, D. Trabalho e educação: fundamentos ontológicos e históricos. Revista Brasileira de Educação, v. 12 n. 34 jan./abr. 2007, p.152-180.

STREECK, W. Buying Time: the delayed crisis of democratic capitalism. Verso, London, New Left Books, 2014

TRASPADINI, R; STEDILE, J. P. Ruy Mauro Marini vida e obra. São Paulo, Expressão Popular, 2005. 